\title{
CDISC SDTM Treatment Failure Reason Terminology
}

National Cancer Institute

\section{Source}

National Cancer Institute. CDISC SDTM Treatment Failure Reason Terminology. NCI Thesaurus. Code C102585.

Terminology associated with the treatment failure reason codelist of the Clinical Data Interchange Standards Consortium (CDISC) Study Data Tabulation Model (SDT M). 